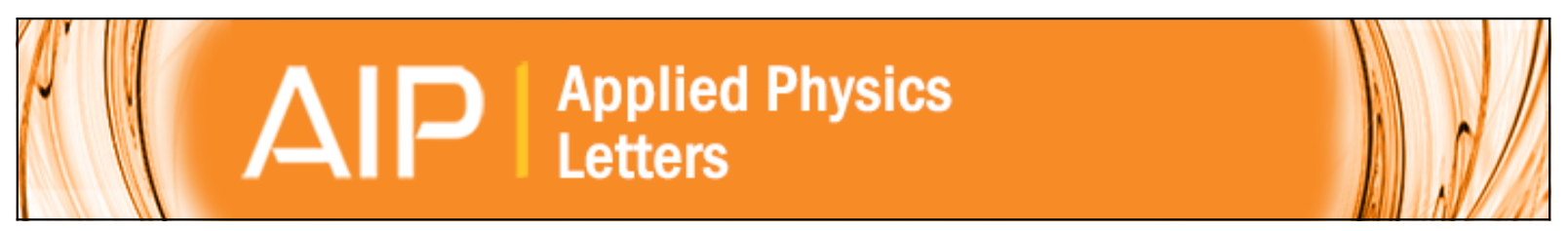

\title{
Disorder improves nanophotonic light trapping in thin-film solar cells
}

U. W. Paetzold, M. Smeets, M. Meier, K. Bittkau, T. Merdzhanova, V. Smirnov, D. Michaelis, C. Waechter, R. Carius, and U. Rau

Citation: Applied Physics Letters 104, 131102 (2014); doi: 10.1063/1.4869289

View online: http://dx.doi.org/10.1063/1.4869289

View Table of Contents: http://scitation.aip.org/content/aip/journal/apl/104/13?ver=pdfcov

Published by the AIP Publishing

\section{$\stackrel{A}{A} \mathbb{P} P$ Re-register for Table of Content Alerts}




\title{
Disorder improves nanophotonic light trapping in thin-film solar cells
}

\author{
U. W. Paetzold, ${ }^{1, a)}$ M. Smeets, ${ }^{1}$ M. Meier, ${ }^{1}$ K. Bittkau, ${ }^{1}$ T. Merdzhanova, ${ }^{1}$ V. Smirnov, ${ }^{1}$ \\ D. Michaelis, ${ }^{2}$ C. Waechter, ${ }^{2}$ R. Carius, ${ }^{1}$ and U. Rau ${ }^{1}$ \\ ${ }^{1}$ IEK5-Photovoltaik, Forschungszentrum Jülich GmbH, 52425 Jülich, Germany \\ ${ }^{2}$ Fraunhofer Institut für Angewandte Optik und Feinmechanik, Albert Einstein Str. 7, D-07745 Jena, Germany
}

(Received 21 January 2014; accepted 3 March 2014; published online 31 March 2014)

\begin{abstract}
We present a systematic experimental study on the impact of disorder in advanced nanophotonic light-trapping concepts of thin-film solar cells. Thin-film solar cells made of hydrogenated amorphous silicon were prepared on imprint-textured glass superstrates. For periodically textured superstrates of periods below $500 \mathrm{~nm}$, the nanophotonic light-trapping effect is already superior to state-of-the-art randomly textured front contacts. The nanophotonic light-trapping effect can be associated to light coupling to leaky waveguide modes causing resonances in the external quantum efficiency of only a few nanometer widths for wavelengths longer than $500 \mathrm{~nm}$. With increasing disorder of the nanotextured front contact, these resonances broaden and their relative altitude decreases. Moreover, overall the external quantum efficiency, i.e., the light-trapping effect, increases incrementally with increasing disorder. Thereby, our study is a systematic experimental proof that disorder is conceptually an advantage for nanophotonic light-trapping concepts employing grating couplers in thin-film solar cells. The result is relevant for the large field of research on nanophotonic light trapping in thin-film solar cells which currently investigates and prototypes a number of new concepts including disordered periodic and quasi periodic textures. (C) 2014 AIP Publishing LLC. [http://dx.doi.org/10.1063/1.4869289]
\end{abstract}

In order to advance the widespread of photovoltaic technologies, production, and material cost of solar cells need to decrease and energy conversion efficiencies need to increase. For both reasons, advanced light-trapping concepts in solar cells are essential since they increase the absorption of incident sunlight in optically thin absorber layers. ${ }^{1-5}$ The resulting enhanced charge carrier generation per absorber volume allows the reduction of material and production costs as well as the increase of the power conversion efficiencies of solar cells. $^{5-10}$ In the last decade, the research on nanophotonic light-trapping concepts making use of periodic nanostructures, such as photonic crystals, ${ }^{11-17}$ grating couplers, ${ }^{18-25}$ or plasmonic gratings, ${ }^{26-31}$ has experienced a vast development including prototyping in thin-film solar cells made of organic materials, ${ }^{15-17,32-34}$ silicon $^{12-14,26-28,35-39}$ and GaAs. ${ }^{40-43}$ The most prominent strategy of employing a periodic nanostructure is to make use of diffractive coupling of incident light to leaky waveguide modes supported by the absorber layers of the solar cells, thereby enhancing the absorption of incident light in the wavelength range of low absorptance. For thin-film silicon solar cells, an improved light-trapping effect of periodically nanostructured prototype solar cells has been reported even in comparison to the state-of-the-art light-trapping concepts which use randomly textured contact layers. $^{26,27,38}$ These results and the broad interest in periodic light-trapping concepts raise a key question which is highly discussed conceptually in recent literature in field of nanophotonic light-trapping: ${ }^{27,36,44-50}$ Is a perfect periodic arrangement of nanostructures in general superior to a disordered arrangement of nanostructures?

\footnotetext{
${ }^{\text {a) }}$ Author to whom correspondence should be addressed. Electronic mail: u.paetzold@fz-juelich.de
}

In order to tackle experimentally this key question for nanophotonic light trapping in thin-film photovoltaics, we study systematically the impact of disorder of initially periodic arrangements of nanostructures as part of an already advanced nanophotonic light-trapping concept of prototype thin-film solar cells based on hydrogenated amorphous silicon (a-Si:H). Due to the low carrier mobility and low absorption of amorphous silicon in a broad energy range, ${ }^{51}$ research on nanophotonic light trapping is very important and advancing for these solar cells. But the light-trapping concepts as well as fabrication methods of nanostructured interfaces are transferrable to other thin-film technologies, too. For example, our advanced nanophotonic light-trapping concept uses a periodically nanostructured contact prepared by nanoimprint lithography ${ }^{26,38,52-56}$ which is an approach followed also in organic photovoltaics. ${ }^{32-34}$

In the first part of this paper, the nanophotonic light trapping of prototype a-Si:H solar cells prepared on the periodically nanostructured front contacts is studied. For the optimized periodic arrangement of the nanostructures, the nanophotonic light-trapping concept is found to be superior compared with the state-of-the-art light-trapping concept using randomly textured $\mathrm{SnO}_{2}: \mathrm{F}$ front contacts (Asahi U-type provided by Asahi Glass Company ${ }^{57}$ ). The nanophotonic light-trapping effect is studied in detail for various periods revealing an enhancement of the external quantum efficiency $(E Q E)$ at distinct wavelengths which we attribute to coupling of incident light to waveguide modes. In a second step, the impact of disorder in the arrangement of the nanostructures on the light-trapping effect in prototype solar cells is studied. Therefore, we incrementally introduce disorder into the periodic arrangement of the nanostructures at the front contact of prototype solar cells. We find that the light-trapping effect, i.e., the $E Q E$ in the wavelength range of low absorption in 
a-Si:H and in turn the short-circuit current density $\left(J_{\mathrm{SC}}\right)$ increase with increasing disorder independent of the period of the nanostructure.

The investigated nanophotonic light-trapping concept uses a front contact which consists of a glass superstrate structured by nanoimprint lithography (details in the supplementary material ${ }^{62}$ ) covered by $80 \mathrm{~nm}$ of aluminum doped zinc oxide ( $\mathrm{ZnO}: \mathrm{Al})$. The reference random light-trapping concept uses commercially available as-grown randomly textured $\mathrm{SnO}_{2}: \mathrm{F}$. The amorphous silicon solar cells of thickness around $270 \mathrm{~nm}$ are prepared on these transparent superstrates by plasma enhanced chemical vapor deposition (details in the supplementary material ${ }^{62}$ ). An $80 \mathrm{~nm}$ thick sputtered $\mathrm{ZnO}: \mathrm{Al}$ layer and a $700 \mathrm{~nm}$ thick Ag layer serve as reflective back contact. In Figures 1(a) and 1(b), scanning electron microcopy images of cross-sections of solar cells deposited on the nanostructured front contact with cubic nanostructures (side length of $150 \mathrm{~nm}$ and period of $400 \mathrm{~nm}$ ) and an as-grown randomly textured $\mathrm{SnO}_{2}: \mathrm{F}$ front contact are shown. The $E Q E$ and absorptance $A$ of these solar cells are shown in Figures $1(\mathrm{c})$ and $1(\mathrm{~d})$, respectively. In the wavelength range from $300 \mathrm{~nm}$ to $700 \mathrm{~nm}$, the EQE of the solar cell with the nanophotonic front contact is enhanced compared to the solar cell with the randomly textured $\mathrm{SnO}_{2}: \mathrm{F}$ front contact. The enhancement in $E Q E$ corresponds to an increase in $J_{\mathrm{SC}}$ from $13.7 \mathrm{~mA} / \mathrm{cm}^{2}$ for the solar cell prepared on the reference random texture to $14.6 \mathrm{~mA} / \mathrm{cm}^{2}$ for the solar cell deposited on the periodically nanostructured front electrode. This enhancement is caused by two effects: (i) Decreased parasitic losses at the front side of the solar cell, since the $E Q E$ of the nanophotonic solar cell is increased despite an decrease in absorptance for wavelengths shorter than $500 \mathrm{~nm}$, where incident light passes at most once through the $270 \mathrm{~nm}$ thick a-Si:H solar cell. ${ }^{6,58}$ (ii) A very good light trapping for wavelengths longer than $500 \mathrm{~nm}$, where the absorptance of a-Si:H decreases strongly and light passes several times through the solar cell. In particular, for incident light in the wavelength range from $550 \mathrm{~nm}$ to $700 \mathrm{~nm}$, the nanophotonic solar cell shows an overall improved light-trapping effect compared with the solar cell deposited on the randomly textured as-grown $\mathrm{SnO}_{2}: \mathrm{F}$ superstrate, since the $E Q E$ of the nanophotonic solar cell is enhanced and the average absorptance of both cells remains comparable. Due to light diffraction at the periodically textured front contact and back reflector of the solar cell, incident light can couple to waveguide modes supported by the amorphous silicon absorber layer. It shall be noted that a small decrease in fill factor $(F F)$ and a significant decrease in open circuit voltage $\left(V_{\mathrm{OC}}\right)$ are observed for the nanophotonic solar cell. This is attributed to enhanced recombination at defects in the intrinsic a-Si:H layer of the nanophotonic solar cell, resulting from growth disturbance on textured superstrates. ${ }^{59}$ Despite the decrease in $V_{\mathrm{OC}}$ and $F F$, the conversion efficiency ( $\mathrm{n}$ ) of the nanophotonic solar cell remains similar compared with the reference solar cell prepared on the randomly textured as-grown $\mathrm{SnO}_{2}: \mathrm{F}$ superstrate, which is driven by the strong increase in $J_{\mathrm{SC}}$ due to the improved light-trapping. Figure 2 shows that a qualitatively similar but weaker light-trapping effect is observed also for nanophotonic solar cells with a periodically nanostructured front contact of periods larger than $400 \mathrm{~nm}$. Down to a period
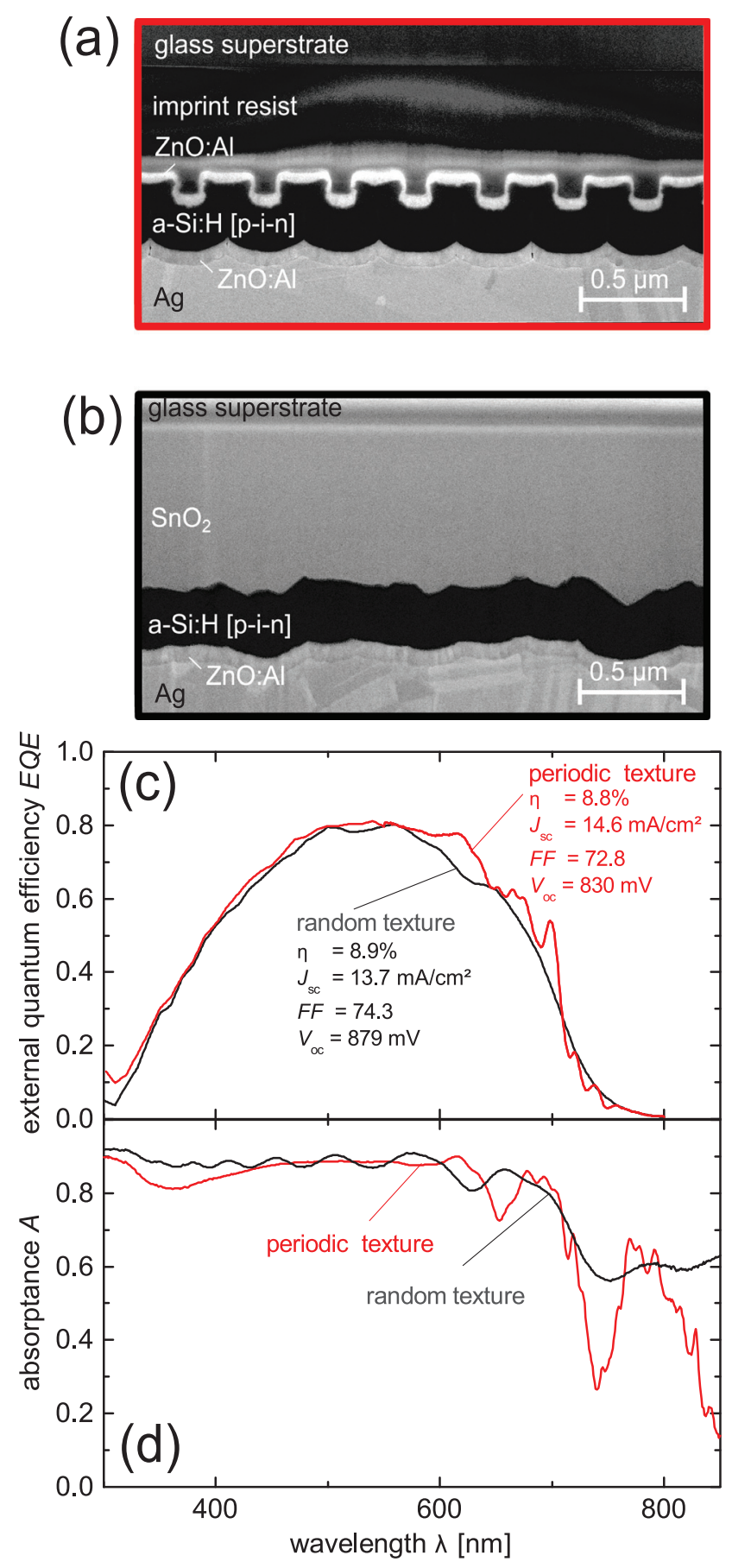

FIG. 1. Scanning electron image of cross sections of (a) a periodically structured a-Si:H solar cells with $400 \mathrm{~nm}$ period and (b) a solar cell with the state-of-the-art random texture. The external quantum efficiency $(E Q E)$ and the absorptance $(A)$ of the solar cells are shown in (a) and (b), respectively.

of $500 \mathrm{~nm}$, the periodically nanostructured front contact out performs the random texture. However, for larger periods $J_{\mathrm{SC}}$ gets lower but continues to stay above $J_{\mathrm{SC}}$ of a flat substrate. For these solar cells, $V_{\mathrm{OC}}$ and $F F$ increase to values similar to the reference solar cell (not shown) but this advantage is overcompensated by the decrease in $J_{\mathrm{SC}}$. Optimizations of deposition conditions, e.g., a decrease of the deposition rate of the a-Si:H layers, are required to improve the $V_{\mathrm{OC}}$ also in nanophotonic solar cells of small periods in order to translate the improved light-trapping effect into significantly improved $\eta$.

Comparing the $E Q E$ and reflectance $R$ of the solar cell prepared on the periodically nanostructured superstrate with 
(a)
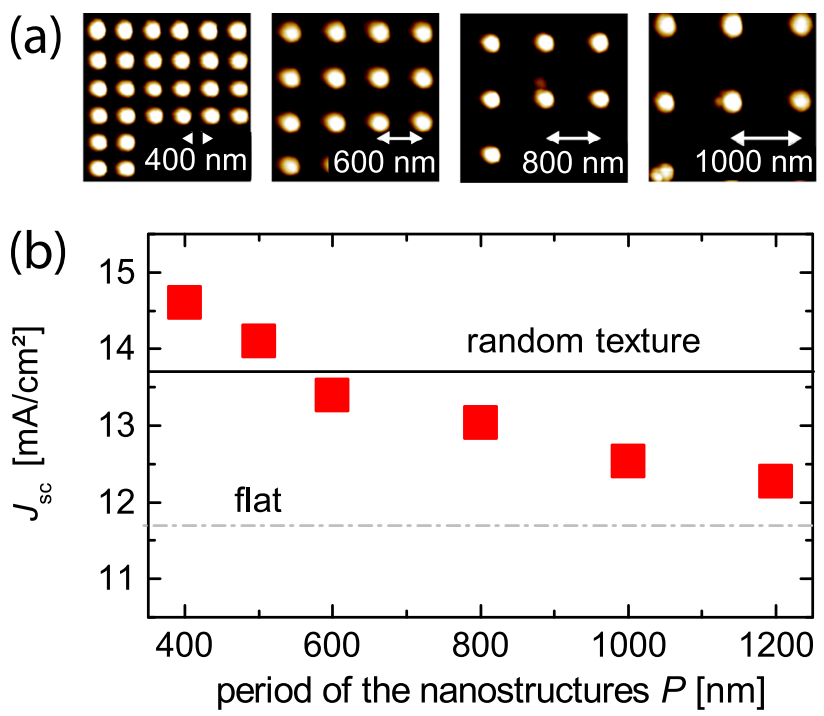

FIG. 2. (a) Surface texture measured by atomic force microscopy of superstrates with periodically arranged cubic nanostructures (side length $150 \mathrm{~nm}$ ) covered with $80 \mathrm{~nm} \mathrm{ZnO:Al.} \mathrm{The} \mathrm{period} \mathrm{of} \mathrm{the} \mathrm{nanostructures} \mathrm{increases}$ from left to right from $400 \mathrm{~nm}, 600 \mathrm{~nm}, 800 \mathrm{~nm}$, to $1000 \mathrm{~nm}$. (b) Shortcircuit current density $J_{\mathrm{SC}}$ of a-Si:H solar cells in superstrate configuration prepared on the surface textures shown in (a) as well as flat superstrates and the state-of-the-art random.

the solar cell prepared on the state-of-the-art randomly textured front contact in Figure 1(c), we identify rather narrow maxima for wavelengths longer than $600 \mathrm{~nm}$ for the nanophotonic solar cell. These maxima are attributed to a strong coupling of incident light to specific leaky waveguide modes supported by the periodically nanostructured a-Si:H absorber layers of the nanophotonic solar cell. ${ }^{22,26,27,38,60,61}$ In Figure 3 , the $E Q E$ and absorptance $A$ of nanophotonic solar cells with periods of $400 \mathrm{~nm}, 500 \mathrm{~nm}$, and $600 \mathrm{~nm}$ are shown at a high resolution for wavelengths from $650 \mathrm{~nm}$ to $750 \mathrm{~nm}$. In this wavelength range, the absorption coefficient of a-Si:H is low enough to allow for the propagation of light, i.e., the formation of waveguide modes, in the a-Si:H absorber layer while the absorption coefficient is large enough to induce a significant $E Q E$ signal on a linear scale. As a result, in this wavelength range the maxima in $A$ can be correlated straight forward to the maxima in EQE (see Figure 3). This way, we show the fundamental relevance of the coupling of incident light to the leaky waveguide modes for the light-trapping effect in the periodically structured nanophotonic solar cells.

In order to study the influence of disorder on the lighttrapping effect of nanophotonic light trapping, we compare in the following solar cells prepared on superstrates with periodically arranged nanostructures and superstrates with nanostructures of the same geometry but in disordered arrangement. To this end, the location of each nanostructure is varied randomly around the middle position of the corresponding unit cells. The displacement obeys an univariant normal distribution, i.e., all nanostructure displacements are in principle stochastically independent and the disorder is only characterized by the conventional standard deviation $\sigma$ which we scale with the original grating period to obtain a relative standard deviation $\left(\sigma_{\text {rel. }}=\sigma /\right.$ period $)$. In order to avoid the coalescence of displaced nanostructures, the nanostructure displacements are limited to a minimum distance between

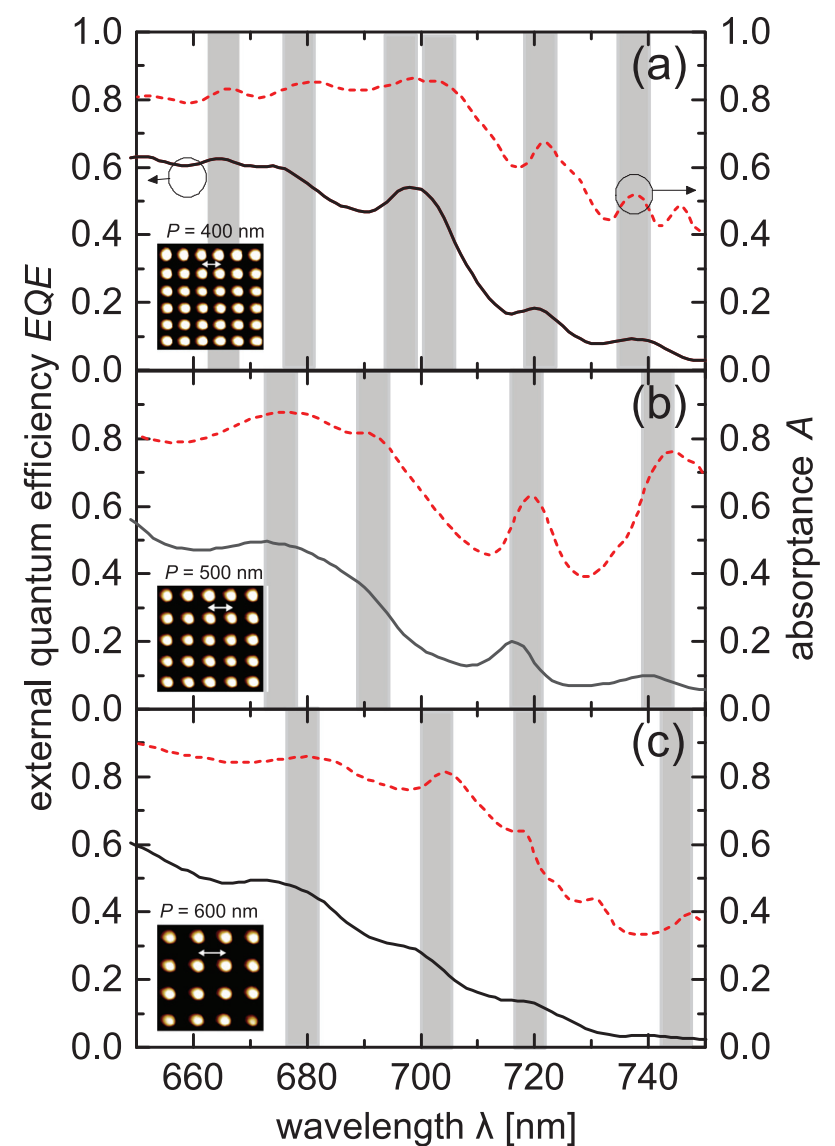

FIG. 3. The external quantum efficiency $(E Q E)$ [black solid line] and absorptance $(A)$ [red line] of solar cells with periodic structure of period $\mathrm{P}$ of (a) $400 \mathrm{~nm}$, (b) $500 \mathrm{~nm}$, and (c) $600 \mathrm{~nm}$. The EQE and $A$ was measured at an angle of incidence of incident light of $0^{\circ}$ and $2^{\circ}$, respectively. The grey bars illustrate the spectral agreement between maxima in $E Q E$ and $A$.

neighboring substructures of $50 \mathrm{~nm}$. This is realized by the rejection method, i.e., all potential stochastic realizations with smaller distances as the minimum value are not considered.

In Figures 4(a) and 4(b), atomic force microscopy images of a superstrate with periodically arranged nanostructures $\left(\sigma_{\text {rel. }}=0\right)$ and a superstrate with nanostructures of the same geometry but in disordered arrangement $\left(\sigma_{\text {rel. }}=0.2\right)$ are shown, respectively. The unit cell of the arrangement of the nanostructures has a period of $500 \mathrm{~nm}$. Figure 4(c) shows the $E Q E$ and absorptance $A$ of the solar cells prepared on these superstrates. For wavelengths shorter than $500 \mathrm{~nm}$, the EQEs are very similar. Since incident light does not pass multiple times through the solar cell for this wavelength range, we conclude that neither the light incoupling at the nanostructured front contact nor parasitic absorption losses in the nanophotonic front electrode are affected significantly by the disordered arrangement of the nanostructures. In contrast, for wavelengths longer than $500 \mathrm{~nm}$, the $E Q E$ of the solar cell prepared on the disordered arrangement of nanostructures is significantly enhanced and also the absorptance is increased in average. Thus, the light-trapping effect of the periodic nanophotonic solar cell is enhanced by introducing disorder, causing an enhancement in $J_{\mathrm{SC}}$ of around $0.6 \mathrm{~mA} / \mathrm{cm}^{2}$. It shall also be noted that the small maxima in the EQE of the nanophotonic solar cell, which correspond to a spectrally selective coupling of incident light to individual leaky waveguide 
(a) periodic

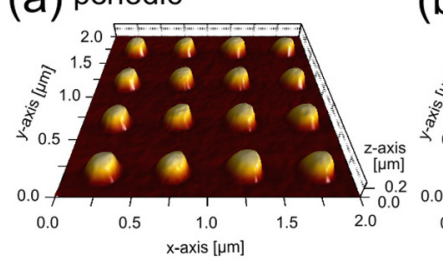

(b)

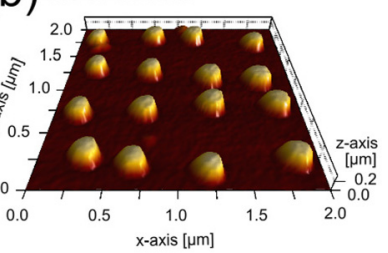

(c)

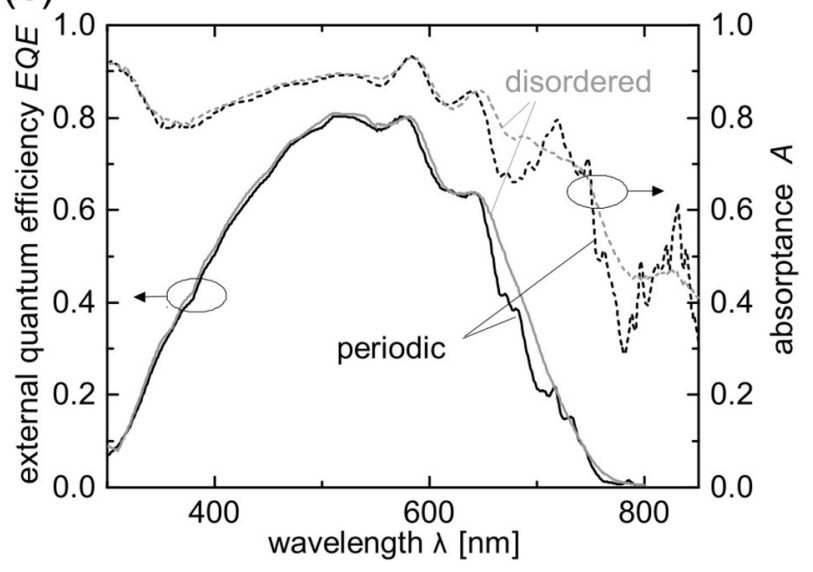

FIG. 4. Surface texture measured by atomic force microscopy of superstrates covered with $80 \mathrm{~nm} \mathrm{ZnO:Al} \mathrm{with} \mathrm{(a)} \mathrm{a} \mathrm{periodic} \mathrm{arrangement} \mathrm{of} \mathrm{the} \mathrm{nano-}$ structures and (b) a disordered arrangement of the nanostructures. The side length of the unit cell is $500 \mathrm{~nm}$. (c) The external quantum efficiency $(E Q E)$ [solid lines] and absorptance $(A)$ [dashed lines] of a-Si:H solar cells in superstrate configuration prepared on the superstrates shown in (a) and (b).

modes, diminish for the disordered arrangement of nanostructures while the total EQE increases.

In order to study the above presented impact of disorder on the nanophotonic light-trapping effect in detail, we study also the incremental increase of disorder of the nanostructures at the front contact. Therefore, a-Si:H solar cells fabricated on six superstrates with incrementally increasing disorder of the nanostructure arrangement for either an average distance of $500 \mathrm{~nm}$ and $800 \mathrm{~nm}$ are compared. AFM images of the nanostructured superstrates of average distance of $500 \mathrm{~nm}$ covered with the $80 \mathrm{~nm}$ thick $\mathrm{ZnO}: \mathrm{Al}$ front contact are shown in Figure 5(a). The disorder of the nanostructures is defined as explained above but the relative standard deviation increases incrementally $\left(\sigma_{\text {rel. }}=0,4 \%, 8 \%, 12 \%, 16 \%\right.$, and $20 \%$ ) which is shown for illustration in Figure 5(b). In Figure 5(c), the EQE of the solar cells are shown in the relevant wavelength range for light trapping from $500 \mathrm{~nm}$ to $800 \mathrm{~nm}$. With increasing disorder of the nanostructures also an incremental increase in $E Q E$ is observed. Beyond this, it is shown that the increasing disorder reduces incrementally the amplitude and increases the width of peaks which correspond to the coupling of incident light to individual waveguide modes. In general, the diminishing of the maxima is attributed to the disorder in the arrangement of the nanostructures which obviates a spectrally selective coupling of incident light to specific waveguide modes. Since the $E Q E$ increases overall with increasing disorder, it can be concluded that a lower spectral selectivity of the light coupling to a specific waveguide modes and thereby a spectrally broader but less strong coupling to individual waveguide modes for a specific
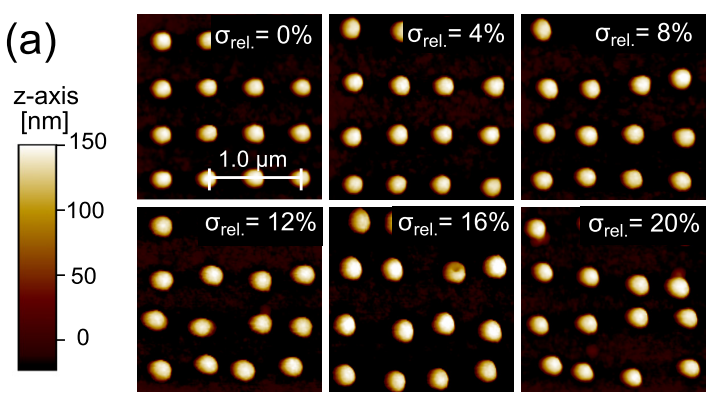

(b)

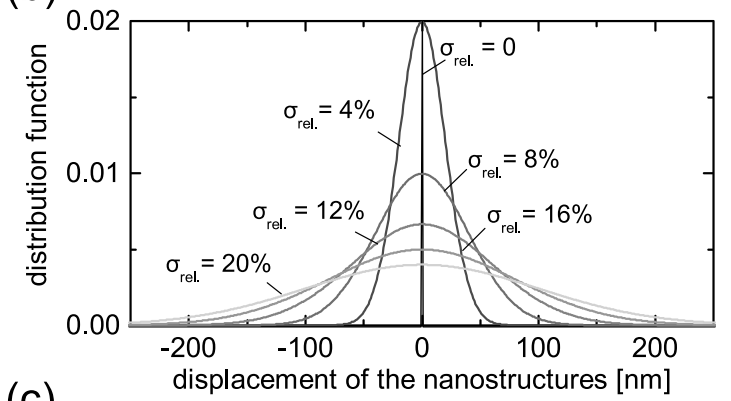

(c)
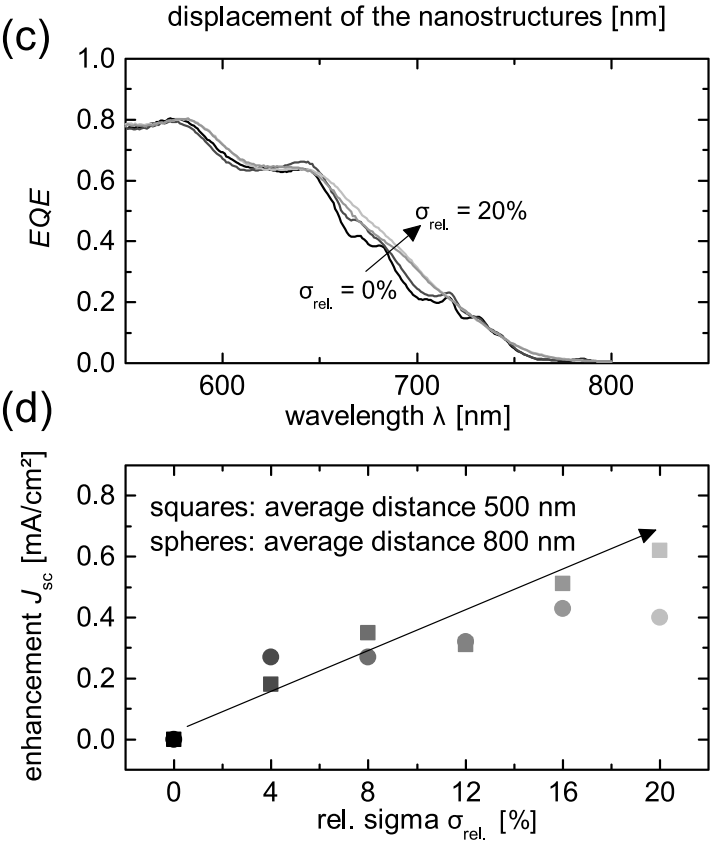

FIG. 5. (a) Surface texture measured by atomic force microscopy of nanostructured superstrates with increasing disorder of the arrangement of the nanostructures. The side length of the unit cell is $500 \mathrm{~nm}$. (b) Gaussian distribution function of the displacement of the nanostructures from the center of periodically arranged unit cells (disorder is specified by the relative standard deviations $\sigma_{\text {rel. }}$ scaled with the period of the original unit cells). (c) The external quantum efficiency $(E Q E)$ [solid lines] and absorptance $(A)$ [dashed lines] and (d) enhancement of the short-circuit current density $J_{S C}(\mathrm{~d})$ of a-Si:H solar cells prepared on the nanostructured superstrates with average distances of neighboring nanostructures of $500 \mathrm{~nm}$ (squares) and $800 \mathrm{~nm}$ (spheres).

wavelength is a clear advantage. The corresponding increase in $J_{\mathrm{SC}}$ as a function of the disorder of the nanostructures is shown in Figure 5(d) for unit cells of the nanostructures of $500 \mathrm{~nm}$ as well as $800 \mathrm{~nm}$ side length.

To answer our key research question of this paper, our central message reads: "Disorder in nanophotonic light concepts bears the potential to improve even advanced periodic nanophotonic light-trapping concepts which are already superior to state-of-the-art random light-trapping concepts." Our study is the first systematic experimental proof that disorder is conceptually an advantage for nanophotonic light-trapping 
concepts employing grating coupler in thin-film solar cells. The result is relevant for the large field of research on nanophotonic light-trapping in thin-film solar cells which currently investigates and prototypes a number of periodic device concepts. ${ }^{11-43}$ Moreover, this study ties in with the very recent so far solely numerical and conceptual studies on disorder in periodic light-trapping concepts. ${ }^{27,36,44-50}$ Our result suggests that an additional potential of improvement can be explored by novel nanophotonic light-trapping concepts if disorder is taken into consideration in the conceptual design.

The authors thank M. Prömpers, D. Weigand, P. Henning, H. Siekmann, U. Gerhards, M. Ermes, A. Hoffmann, S. Lehnen, T. Kirchartz, F. Fingers, A. Lamertz, E. Moulin, and J. Hüpkes for the support and fruitful discussions. A part of this work was carried out in the framework of the FP7 project "Fast Track," funded by the EC (Grant No. 283501) and by the BMBF through the project "PhoNa" (Grant No. 03ISS2101D).

${ }^{1}$ M. A. Green, Solar Cells: Operating Principles, Technology and System Applications (Prentice-Hall, New Jersey, USA, 1986).

${ }^{2} \mathrm{R}$. Brendel, Thin-Film Crystalline Silicon Solar Cells (Wiley-VCH, Weinheim, Germany, 2005).

${ }^{3}$ D. Redfield, Appl. Phys. Lett. 25, 647 (1974).

${ }^{4}$ E. Yablonovitch, J. Opt. Soc. 72, 899 (1982).

${ }^{5}$ P. Campbell and M. A. Green, J. Appl. Phys. 62, 243 (1987).

${ }^{6}$ J. Müller, B. Rech, J. Springer, and M. Vanecek, Sol. Energy 77, 917 (2004).

${ }^{7}$ E. T. Yu and J. van de Lagemaat, MRS Bull. 36, 424 (2011).

${ }^{8}$ S. Mokkapati and K. R. Catchpole, J. Appl. Phys. 112, 101101 (2012).

${ }^{9}$ H. A. Atwater and A. Polman, Nature Mater. 9, 205 (2010).

${ }^{10}$ M. A. Green and S. Pillai, Nat. Photonics 6, 130 (2012).

${ }^{11}$ P. Bermel, C. Luo, L. Zeng, L. C. Kimerling, and J. D. Joannopoulos, Opt. Express 15, 16986 (2007).

${ }^{12}$ L. Zeng, P. Bermel, Y. Yi, B. A. Alamariu, K. A. Broderick, J. Liu, C. Hong, X. Duan, J. Joannopoulos, and L. C. Kimerling, Appl. Phys. Lett. 93, 221105 (2008).

${ }^{13}$ J. Üpping, A. Bielawny, R. B. Wehrspohn, T. Beckers, R. Carius, U. Rau, S. Fahr, C. Rockstuhl, F. Lederer, M. Kroll, T. Pertsch, L. Steidl, and R. Zentel, Adv. Mater. 23, 3896 (2011).

${ }^{14}$ D. Zhou and R. Biswas, J. Appl. Phys. 103, 093102 (2008).

${ }^{15}$ D. H. Ko, J. R. Tumbleston, L. Zhang, S. Williams, J. M. DeSimone, R. Lopez, and E. T. Samulski, Nano Lett. 9, 2742 (2009).

${ }^{16}$ D. H. Ko, J. R. Tumbleston, A. Gadisa, M. Aryal, Y. C. Liu, R. Lopez, and E. T. Samulski, J. Mater. Chem. 21, 16293 (2011).

${ }^{17}$ S. Guldin, S. Hüttner, M. Kolle, M. E. Welland, P. Müller-Buschbaum, R. H. Friend, U. Steiner, and N. Tétreault, Nano Lett. 10, 2303 (2010).

${ }^{18}$ I. Tobías, A. Luque, and A. Martí, J. Appl. Phys. 104, 034502 (2008).

${ }^{19}$ Z. Yu, A. Raman, and S. Fan, Opt. Express 18(S3), A366-A380 (2010).

${ }^{20}$ C. Haase and H. Stiebig, Appl. Phys. Lett. 91, 061116 (2007).

${ }^{21}$ C. Eisele, C. E. Nebel, and M. Stutzmann, J. Appl. Phys. 89, 7722 (2001).

${ }^{22}$ C. S. Schuster, P. Kowalczewski, E. R. Martins, M. Patrini, M. G. Scullion, M. Liscidini, L. Lewis, C. Reardon, L. C. Andreani, and T. F. Krauss, Opt. Express 21, A433 (2013).

${ }^{23}$ N. N. Feng, J. Michel, L. Zeng, J. Liu, H. Ching-Yin, L. C. Kimerling, and X. Duan, IEEE Trans. Electron Devices 54, 1926 (2007).

${ }^{24}$ K. X. Wang, Z. Yu, V. Liu, Y. Cui, and S. Fan, Nano Lett. 12, 1616 (2012).

${ }^{25}$ S. C. Kim and I. Sohn, J. Opt. Soc. Korea 14, 142 (2010).

${ }^{26}$ V. E. Ferry, M. A. Verschuuren, H. B. T. Li, E. Verhagen, R. J. Walters, R. E. I. Schropp, H. A. Atwater, and A. Polman, Opt. Express 18, A237 (2010).

${ }^{27}$ V. E. Ferry, M. Verschuuren, C. van Lare, R. Schropp, H. A. Atwater, and A. Polman, Nano Lett. 11, 4239 (2011).

${ }^{28}$ J. Bhattacharya, N. Chakravarty, S. Pattnaik, W. Slafer, R. Biswas, and V. L. Dalal, Appl. Phys. Lett. 99, 131114 (2011).

${ }^{29}$ U. W. Paetzold, E. Moulin, B. E. Pieters, R. Carius, and U. Rau, Opt. Express 19, A1219 (2011).
${ }^{30}$ U. W. Paetzold, E. Moulin, B. E. Pieters, U. Rau, and R. Carius, J. Photonics Energy 2, 027002 (2012).

${ }^{31}$ S. Mokkapati, F. J. Beck, A. Polman, and K. R. Catchpole, Appl. Phys. Lett. 95, 053115 (2009).

${ }^{32}$ P. C. Tseng, M. H. Hsu, M. A. Tsai, C. W. Chu, H. C. Kuo, and P. Yu, Org. Electron. 12, 886 (2011).

${ }^{33}$ D. H. Wang, D. G. Choi, K. J. Lee, J. H. Jeong, S. H. Jeon, O. Park, and J. H. Park, Org. Electron. 11, 285 (2010).

${ }^{34}$ S. Y. Chou and W. Ding, Opt. Express 21, A60 (2013).

${ }^{35}$ J. Zhu, C. M. Hsu, Z. Yu, S. Fan, and Y. Cui, Nano Lett. 10, 1979 (2010).

${ }^{36}$ C. Battaglia, C. M. Hsu, K. Söderström, J. Escarré, F. J. Haug, M. Charrière, M. Boccard, M. Despeisse, D. T. L. Alexander, M. Cantoni, Y. Cui, and C. Ballif, ACS Nano 6, 2790 (2012).

${ }^{37}$ H. Sai, H. Fujiwara, M. Kondo, and Y. Kanamori, Appl. Phys. Lett. 93, 143501 (2008).

${ }^{38}$ U. W. Paetzold, E. Moulin, D. Michaelis, W. Bottler, C. Wachter, V. Hagemann, M. Meier, R. Carius, and U. Rau, Appl. Phys. Lett. 99, 181105 (2011).

${ }^{39}$ J. Kim, A. Hong, J. W. Nah, B. Shin, F. M. Ross, and D. K. Sadana, ACS Nano 6, 265 (2012).

${ }^{40}$ K. S. Cho, P. Mandal, K. Kim, I. H. Baek, S. Lee, H. Lim, D. J. Cho, S. Kim, J. Lee, and F. Rotermund, Opt. Commun. 284, 2608 (2011).

${ }^{41}$ G. Kang, H. Park, D. Shin, S. Baek, M. Choi, D. H. Yu, K. Kim, and W. J. Padilla, Adv. Mater. 25, 2617 (2013).

${ }^{42}$ C. B. Honsberg and A. M. Barnett, in Proceedings of the 22nd IEEE Photovoltaic Specialists Conference (1991), Vol. 1, p. 262.

${ }^{43}$ J. Grandidier, D. M. Callahan, J. N. Munday, and H. A. Atwater, IEEE J. Photovoltaics 2, 123 (2012).

${ }^{44}$ E. R. Martins, J. Li, Y. Liu, V. Depauw, Z. Chen, J. Zhou, and T. F. Krauss, Nat. Commun. 4, 2665 (2013).

${ }^{45}$ R. A. Pala, J. S. Q. Liu, E. S. Barnard, D. Askarov, E. C. Garnett, S. Fan, and M. L. Brongersma, Nat. Commun. 4, 2095 (2013).

${ }^{46}$ R. Peretti, G. Gomard, L. Lalouat, C. Seassal, and E. Drouard, Phys. Rev. A 88, 053835 (2013).

${ }^{47}$ A. Bozzola, M. Liscidini, and L. C. Andreani, "Broadband light trapping with disordered photonic structures in thin-film silicon solar cells," Progress in Photovoltaics: Research and Applications.

${ }^{48}$ A. Oskooi, P. A. Favuzzi, Y. Tanaka, H. Shigeta, Y. Kawakami, and S. Noda, Appl. Phys. Lett. 100, 181110 (2012).

${ }^{49}$ M. Burresi, F. Pratesi, K. Vynck, M. Tormen, and D. S. Wiersma, Opt. Express 21, A268 (2013).

${ }^{50}$ F. Pratesi, M. Burresi, F. Riboli, K. Vynck, and D. S. Wiersma, Opt. Express 21, A460 (2013).

${ }^{51}$ S. Reynolds, R. Carius, F. Finger, and V. Smirnov, Thin Solid Films 517, 6392 (2009).

${ }^{52}$ J. Escarré, C. Battaglia, K. Söderström, C. Pahud, R. Biron, O. Cubero, F.-J. Haug, and C. Ballif, J. Opt. 14, 024009 (2012).

${ }^{53}$ A. Bessonov, Y. Cho, S.-J. Jung, E.-A. Park, E.-S. Hwang, J.-W. Lee, M. Shin, and S. Lee, Sol. Energy Mater. Sol. Cells 95, 2886 (2011).

${ }^{54}$ K. Söderström, J. Escarré, O. Cubero, F.-J. Haug, S. Perregaux, and C. Ballif, Prog. Photovoltaics 19, 202 (2011).

${ }^{55}$ M. Meier, U. W. Paetzold, M. Prömpers, T. Merdzahnova, R. Carius, and A. Gordijn, "UV nanoimprint for the replication of etched $\mathrm{ZnO}$ :Al textures applied in thin-film silicon solar cells," Progress in Photovoltaics: Research and Applications (published online).

${ }^{56}$ U. W. Paetzold, W. Zhang, M. Prömpers, J. Kirchhoff, T. Merdzhanova, S. Michard, R. Carius, A. Gordijn, and M. Meier, Mater. Sci. Eng., B 178, 617 (2013).

${ }^{57}$ N. Taneda, K. Masumo, M. Kambe, T. Oyama, and K. Sato, in Proceedings of the 23rd European Photovoltaic Solar Energy Conference and Exhibition (2008), p. 2084.

${ }^{58}$ J. Müller, O. Kluth, S. Wieder, H. Siekmann, G. Schöpe, W. Reetz, O. Vetterl, D. Lundszien, A. Lambertz, F. Finger, B. Rech, and H. Wagner, Sol. Energy Mater. 66, 275 (2001).

${ }^{59}$ T. Söderström, F. J. Haug, V. Terrazzoni-Daudrix, and C. Ballif, J. Appl. Phys. 103, 114509 (2008).

${ }^{60}$ A. Naqavi, F. J. Haug, C. Battaglia, H. P. Herzig, and C. Ballif, J. Opt. Soc. Am. B 30, 13-20 (2013).

${ }^{61}$ F. J. Haug, K. Söderström, A. Naqavi, and C. Ballif, "Resonances and absorption enhancement in thin film silicon solar cells with periodic interface texture," J. Appl. Phys. 109, 084516 (2011).

${ }^{62}$ See supplementary material at http://dx.doi.org/10.1063/1.4869289 for additional information on the replication of nanostructured superstrates by nanoimprint lithography, preparation of a-Si:H thin-film solar cells, high resolution external quantum efficiency, and reflectance measurements. 